\title{
Reasentamiento tras el desplazamiento forzado: dos comunidades étnicas en Colombia*
}

\section{Resettlement after forced displacement: Two ethnic Colombian communities}

\author{
Philippe Chenut Correa ${ }^{* *}$ \\ Universidad del Externado de Colombia, Bogotá, Colombia \\ ORCID: https://orcid.org/o000-0002-6315-7115 \\ Myriam Ocampo Prado \\ Universidad Javeriana, Bogotá, Colombia \\ ORCID: https://orcid.org/oooo-0002-I817-6798
}

ISSN: ISSN-OI85-4259; e-ISSN: 2007-9I76

DOI: http://dx.doi.org/I0.28928/ri/7620I4/atc4/chenutcorreap/ocampopradom

\section{Resumen}

Los desplazados deben construir, rápidamente y en condiciones precarias, una relación con su nuevo territorio, al tiempo que el reasentamiento puede inducir cambios percibidos de diferentes maneras por los antiguos residentes. Este proceso de reterritorialización se estudia para dos comunidades distintas: afrocolombianos de la región conocida como el Medio Atrato en el Departamento del Chocó, y campesinos-indígenas de la etnia Nasa provenientes de la región del Alto Naya. Palabras Clave: migración forzada, reterritorialización, afrocolombianos, campesinos-indígenas Nasa

\footnotetext{
Abstract

Displaced persons have to establish, in a short time and precarious conditions, a relationship with their new territory, while at the same time their resettlement can provoke changes perceived differently by the existing residents. In this article, the process of reterritorialization is studied based on two distinct communities: Afro-Colombians displaced from Medio Atrato region, situated on The Chocó Department, and peasants-indigenous from the Nasa ethnic group displaced from Alto Naya region, situated on the Cauca Department.Key words forced migration, reterritorialization, Afro-Colombians, Nasa peasant-indigenous
}

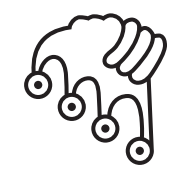

\section{IZTAPALAPA}

Agua sobre lajas

Trabajo propio de las actividades de investigación del Grupo "Procesos sociales, territorios y medio ambiente", Centro de Investigaciones sobre Dinámica Social (cIDs), de la Facultad de Ciencias Sociales y Humanas de la Universidad Externado de Colombia. En el equipo también participaron Mayerlín Fergusson López, y Mabel Martínez Carpeta.

** Docente-investigador, Universidad Externado de Colombia. pchenutc@gmail.com

*** Docente en la Pontificia Universidad Javeriana, Instituto Pensar en Extensión Universitaria, Colombia myriamocampo@yahoo.com.mx 


\section{Introducción}

1 desplazamiento forzado se ha convertido en una de las más graves con-
secuencias del conflicto armado que perdura en Colombia desde hace más
de medio siglo. Los motivos subyacentes al desplazamiento y la vulneración de los derechos de los desplazados han recibido mucha atención, en cambio la relación con el nuevo territorio en el que han de vivir ha sido menos estudiada. Este hecho es particularmente relevante en la medida en que las perspectivas de retorno de los desplazados a sus lugares de origen son inciertas y tampoco garantizarían necesariamente el restablecimiento de los derechos vulnerados de los desplazados (Naranjo, s.f. . $_{\text {. }}$

Los desplazados han perdido su lugar de residencia, sus actividades productivas tradicionales, su red de relaciones sociales de vecindad inmediata. Deben instalarse en lugares frecuentemente muy diferentes a los de origen y construir, rápidamente y en condiciones precarias, una relación con su nuevo territorio. Los sitios de reasentamiento no son por lo general lugares despoblados, lo que lleva a preguntarse también por los cambios sucedidos tras la llegada de los desplazados y la visión que los antiguos residentes tienen de estos cambios. Esta problemática se aborda para desplazados pertenecientes a dos comunidades étnicas ${ }^{1}$ diferentes: afrocolombianos provenientes en su mayoría de la región del Medio Atrato en el Departamento del Chocó, en el Pacífico colombiano, reasentados en el sector de Tibabuyes de la

1 La cuestión de la etnicidad no se va a abordar aquí. Señalemos simplemente que se asume como elemento diferencial de un grupo étnico como es definido por Barth, para quien éste "cuenta con unos miembros que se identifican a sí mismos y son identificados por otros como constituyentes de una categoría, distinguible de otras categorías del mismo orden" (Ramírez, 2002). Dentro de esta nueva perspectiva de la teoría de la etnicidad, se contrasta la categorización objetiva con la subjetiva y se enfatiza que "los grupos étnicos son categorías de adscripción e identificación que son utilizados por los actores mismos y tienen, por tanto, la característica de organizar la interacción entre los individuos" (Ramírez, 2002). 
localidad bogotana de Suba, y campesinos-indígenas de la etnia Nasa provenientes del Alto Naya en el Departamento del Cauca, suroccidente colombiano, residentes actualmente en el predio rural denominado La Laguna, situado en el municipio de Timbío (Departamento del Cauca).

El estudio del proceso de reasentamiento de personas desplazadas pertenecientes a grupos étnicos reviste un interés particular. A diferencia de otros grupos de desplazados, como los campesinos, la territorialidad en las que estaban inmersos antes del desplazamiento se caracteriza por un conjunto de elementos asociados a su manera particular de ver el mundo, distante de la de comunidades campesinas que también han sido víctimas del desplazamiento forzado.

El enfoque del trabajo se orienta a estudiar la nueva construcción del territorio -la reterritorialización- por parte de los desplazados, desde la perspectiva de su experiencia y de su manera de entender el proceso de reasentamiento. En este orden de ideas, los instrumentos utilizados para recuperar la información pertinente incluyen entrevistas a profundidad en el caso de los afrocolombianos y dos entrevistas grupales ${ }^{2}$ con los campesinos-indígenas, ejercicios de cartografía social, recorridos realizados con los desplazados y georreferenciación de los sitios frecuentados por ellos. Para estudiar cómo los antiguos residentes perciben las cambios sucedidos tras la llegada de los desplazados se utilizó una encuesta, complementada con notas de campo, y un ejercicio de cartografía social realizado con un grupo de residentes de la localidad de Suba. Las diferencias metodológicas en la recolección de información de los dos grupos de desplazados provienen de la voluntad misma de la comunidad de campesinos-indígenas que hoy conforman el cabildo Kitek Kiwe (la tierra floreciente ${ }^{3}$ ) de construir conocimiento en los términos que ellos juzgaron más adecuados.

La selección de estos dos estudios de caso tuvo en cuenta la relevancia y la amplia difusión de dos eventos muy conocidos del conflicto armado colombiano que afectaron a estos dos grupos de desplazados: la masacre del Alto Naya, cometida por un grupo paramilitar durante la Semana Santa del año 200I (García y Jaramillo,

2 Se realizó una primera entrevista, cuyos resultados fueron sistematizados y utilizados luego en un segunda entrevista grupal en la que se discutieron los resultados de la primera y se profundizó en aspectos que no pudieron ser tratados con el suficiente detenimiento en la primera, especialmente en el desarrollo y los efectos de la introducción de los cultivos de coca en el Alto Naya.

3 La comunidad del Cabildo Kitek Kiwe utiliza el término tierra (ver por ejemplo el sitio web del Cabildo). También es frecuente encontrar territorio como traducción del término nasa yuwe (la lengua nasa) kiwe. 
2008) y la destrucción del templo católico de Bojayá el 2 de mayo de 2002, mediante un cilindro bomba disparado por guerrilleros de las FARC, la cual produjo la muerte de II9 personas y dejó heridas a otras II4 (Defensoría del Pueblo, 2002). Estos dos casos de reasentamiento tras el desplazamiento forzado aportan elementos diferentes a los que se pueden encontrar en casos de migración voluntaria, producida por razones esencialmente económicas de poblaciones no pertenecientes a grupos étnicos. El desplazamiento forzado supone una ruptura brutal con el territorio, que por lo general se idealiza después en el lugar de reasentamiento. Esta nostalgia y el recuerdo selectivo de aquello que hacía agradable y daba sentido a la existencia van a jugar un papel crucial en la construcción de una nueva territorialidad en el nuevo sitio de residencia. En el caso de miembros de grupos étnicos la ruptura es aún mayor, ya que se debe pasar por lo general de un modo colectivo de propiedad de la tierra a la apropiación privada. Tras la selección de los dos casos presentados está la voluntad de incluir a dos poblaciones pertenecientes a los dos grupos étnicos de Colombia: los afrocolombianos y los indígenas. Los dos casos permiten también hacer una lectura cruzada del proceso de reasentamiento en la periferia de una gran ciudad como Bogotá y un área rural como la de Timbío, una situación poco frecuente en los procesos de reasentamiento en Colombia, en donde predomina la migración del campo a la ciudad tras el desplazamiento forzado (Alfonso, 20II).

Este trabajo se enmarca dentro del desarrollo del Proyecto de investigación "Desplazamiento forzado y territorio: interacciones y transformaciones" financiado por la Universidad Externado de Colombia y el Departamento Administrativo de Ciencia y Tecnología, Colciencias. El equipo pluridisciplinario de investigadores del proyecto (psicología, geografía, antropología principalmente, pero también ciencia política y derecho) inició sus actividades formales en febrero del 20io. Además de los dos estudios de caso presentados en este artículo, el proyecto incluye otros dos: mujeres cabeza de familia reasentadas en la ciudad de Montería, en el Caribe colombiano, y campesinos reasentados en la ciudad de Cúcuta, ciudad fronteriza con Venezuela. El objetivo general planteado inicialmente en el proyecto buscaba tanto comprender las dimensiones material y simbólica de la relación de los desplazados establecen con sus nuevos territorios, como la percepción que los antiguos residentes en los territorios donde se reubican los desplazados respecto de las transformaciones del territorio inducidas por la llegada de las poblaciones que han sido desarraigadas del suyo propio.

En este artículo se presentan, desde una perspectiva comparativa, los principales hallazgos sobre el proceso de reasentamiento de dos comunidades: afrocolombianos 
y campesinos-indígenas Nasa y la visión que los antiguos residentes tienen sobre los cambios ocurridos durante el proceso.

Se comenzará con una breve contextualización sobre las comunidades y sus territorios de origen y las circunstancias del desplazamiento sufrido, así como las características de los lugares de reasentamiento. Por último, se ha hará una breve reflexión sobre las diferencias entre los dos estudios de caso. El mapa i muestra la localización de los dos estudios de caso, en la ciudad de Bogotá, donde se sitúa el sector de Tibabuyes de la localidad de Suba, y el casco urbano del municipio de Timbío, una población del suroccidente colombiano.

\section{Territorio, territorialidad, lugar}

En las líneas siguientes aparecen con frecuencia los términos de territorio y lugar, que serán discutidos muy brevemente. Esta discusión no pretende hacer un condensado de los ríos de tinta que han hecho correr estos dos conceptos; su propósito es más bien resaltar los puntos que se revelaron importantes en el curso de la investigación.

Territorio y lugar son dos conceptos centrales en geografía que dan cuenta, desde puntos de partida diferentes, de la relación que los grupos humanos construyen y establecen con la superficie terrestre. Desde la orilla del territorio, se privilegió primero el estudio de las relaciones de poder, dominio y control, mientras que en la perspectiva del lugar se hizo énfasis en la experiencia, las prácticas, los lazos afectivos y los significados que le son atribuidos. No obstante, con el paso del tiempo, el estudio del territorio se enriqueció con la incorporación de dimensiones que habían sido en principio asociadas al lugar (Lévy, 2003); al mismo tiempo, el interés por los procesos de producción de los lugares llevó a reivindicar la importancia de la naturaleza conflictiva en las relaciones sociales y del carácter asimétrico de las relaciones de poder involucradas (Cresswell, 2009). Los dos conceptos son polisémicos y en algunas concepciones particulares pueden ser leídos como convergentes. A pesar de ello, los orígenes y las herencias epistemológicas pesan demasiado, y ello hace que dentro de la geografía difícilmente se puedan aceptar lugar y territorio como sinónimos. Numerosas concepciones de territorio lo definen como un espacio apropiado, (entre otros, véase Le Berre, 1992), e insisten en que la apropiación no se refiere sólo a vínculos de propiedad como porción de la superficie terrestre apropiada por un grupo social para garantizar su reproducción y la satisfacción de sus necesidades vitales, sino también a los lazos subjetivos de identidad y afecto existentes entre el sujeto y su territorio. 


\section{Mapa I}

Localización de los estudios de caso

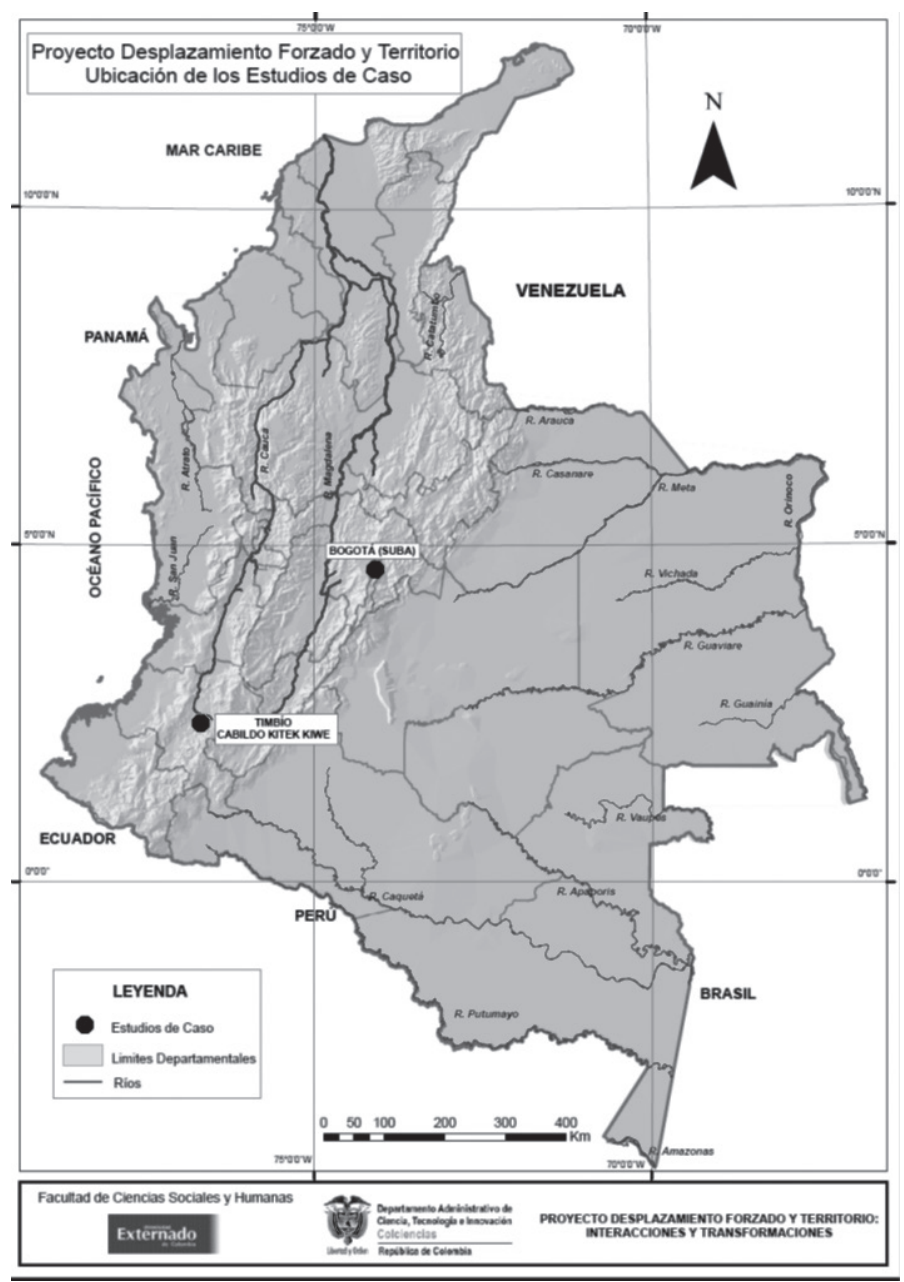

Fuente: Elaboración propia con datos del SIG-Oт del Instituto Geográfico Agustín Codazzi de Colombia (IGAC), adaptado de la cartografía del Proyecto Desplazamiento Forzado y Territorio: Interacciones y Transformaciones. 
A pesar de que a veces se haga un mayor énfasis en la capacidad de ejercer poder y conseguir recursos, o en cambio, en construir significados y lazos afectivos a través de las prácticas de la vida cotidiana, los conceptos de territorio y lugar ponen en primer plano la importancia de la relación que los seres humanos construyen con la superficie terrestre y los objetos que hay en ella. Unos objetos que no tienen un rol pasivo, sino que contribuyen a transformar a los sujetos que interactúan con ellos (Thrift, 1996).

En el desarrollo de la investigación hay momentos en los que se utilizó el término de territorio y otras veces el de lugar. La elección de un término u otro trata de aplicar el siguiente principio general, inspirado en buena parte en las ideas de Guy Mercier (2009) sobre la dialéctica del poder intrínseco y el poder extrínseco en la construcción del territorio y del lugar ${ }^{4}$ y la conceptualización de Debarbieux (2003) del territorio como recurso material y simbólico, fuente de identidad.

La utilización del término territorio se prefiere cuando las relaciones de poder o la capacidad de obtener recursos o de desplegar la potencia de vida del sujeto deben ser resaltadas. En cambio, el término de lugar se utilizará cuando se quiera hacer énfasis en la creación de significados, la construcción y la reconstrucción de la identidad y los resultados de las acciones de múltiples actores que ejercen influencias a veces contradictorias.

Como lo señala Haesbaert (2004), el territorio es algo inacabado, es una realidad en permanente movimiento, sometida a procesos de dominio y control (político-económico) y/o de apropiación (simbólico-cultural) que realizan los grupos humanos en un espacio determinado. Así, cuando se construye territorio, un grupo humano debe hacerlo suyo, aprender a conocerlo, adquirir las habilidades para recorrerlo, identificar y utilizar los recursos que él ofrece, evitar sus peligros, pero también nombrarlo, establecer relaciones afectivas y emotivas con él y darle sentido. Estas relaciones pueden ser entendidas como territorialidad; la cual, no sólo afecta los objetos geográficos, sino que también transforma a los sujetos. Una transformación

4 Mercier (2009) plantea que el territorio existe cuando una sociedad, un grupo o aun una sola persona ejerce directamente, o mediante el concurso de seres geográficos bajo su influencia, algún tipo de control sobre una unidad espacial, sobre los seres geográficos que ella contiene y sobre los que están afuera, pero que quisieran entrar o cuya entrada fuera deseada por alguien. En cambio, el lugar existe cuando un sujeto humano o los seres geográficos bajo su dominio soportan por determinación indirecta la influencia más o menos intensa de otro sujeto o de otro ser geográfico. 
indispensable, si se piensa dentro del marco del proceso de superar la condición de desplazado.

\section{Los desplazados}

En el marco de la investigación, el desplazado es un persona migrante que ha cambiado su lugar de residencia involuntariamente dentro del territorio nacional ante situaciones propias de conflictos armados, tensiones interiores, violencia generadora de violaciones masivas a los derechos humanos surgida cuando grupos paramilitares, guerrillas, bandas delincuenciales y fuerza pública estatal despliegan múltiples formas de confrontación. Una conceptualización operativa del concepto de desplazado plantea un gran reto, dado que las definiciones normativas suponen el cumplimiento de requisitos que no todos los desplazados pueden cumplir. En esencia se exige que el motivo principal del desplazamiento haya sido la violencia, algo muy difícil de evaluar cuando se trata de un complejo fenómeno multicausal como el del desplazamiento forzado. Por esta razón se decidió utilizar el autorreconocimiento como criterio para identificar a los desplazados.

\section{Los afrocolombianos reasentados en un sector de la localidad de Suba}

En este estudio de caso se trabajó con población afrocolombiana ${ }^{5}$ que ha migrado desde sus territorios de origen ${ }^{6}$ a la localidad de Suba dentro del Distrito Capital de Bogotá, específicamente en la Unidad de Planeamiento Zonal (UPZ) Tibabuyes. Esta es una de las dos zonas que más desplazados afrocolombianos ha recibido en

5 Para la Cátedra de Estudios Afrocolombianos (Ministerio de Educación Nacional, 200I), el etnónimo afrocolombiano nace de la necesidad de un grupo y sus individuos de poseer una identidad referencial, construida sobre elementos objetivos y/o subjetivos; implica una resignificación, un reconocimiento del hombre negro, de su humanidad, de sus raíces culturales africanas y colombianas.

6 En muchos contextos, como el que nos ocupa aquí, cuando se habla del Pacífico colombiano no se hace una referencia estricta a las áreas que drenan sus aguas al océano Pacífico. Numerosas zonas del Chocó y aún del noroccidente de Antioquia -el valle del Atrato, por ejemplo- que hacen parte de la cuenca del Caribe comparten muchas características físico-bióticas y socio-económicas con el Pacífico hidrográfico. 
la localidad de Suba (Agencia Presidencial para la Acción Social, 2009). Actualmente, la población afrocolombiana tiene un asentamiento significativo en la región del Pacífico, donde conservan con persistencia las tradiciones culturales y el consiguiente autorreconocimiento como negros; este proceso fue favorecido y fortalecido a partir de la reivindicación de la multiculturalidad y de los derechos específicos de las comunidades étnicas en Colombia, en la Constitución Política de 199i. Los afrocolombianos se encuentran entre los grupos más afectados por el desplazamiento forzado en Colombia. Según datos de la Consultoría para los Derechos Humanos y el Desplazamiento (CodHes, 2009), el I2.3\% de los afrocolombianos se encontraba en situación de desplazamiento forzado y representaba el $22.5 \%$ de la población desplazada del país. Las múltiples presiones sobre sus territorios colectivos (dinámica del conflicto armado, establecimiento de cultivos ilícitos y corredores para el tráfico de drogas y de armas, establecimiento de grandes cultivos agroindustriales, voluntad de apropiarse de tierras asociada a la expectativas generadas por grandes proyectos de infraestructura), previstas en la Ley 70 de 1993, han favorecido esta situación, con el concurso de la incapacidad y/o la falta de voluntad del Estado colombiano para enfrentarla. ${ }^{7}$

Para el estudio de caso en referencia se trabajó con 15 personas desplazadas, I2 mujeres y 3 hombres aceptaron participar en la realización de la entrevista en profundidad; 13 personas participaron en los ejercicios de georreferenciación de los lugares frecuentados, entre ellos Io mujeres y 3 hombres; 7 mujeres y 4 hombres participaron en el ejercicio de cartografía social. Como muestra el mapa 2, estos pobladores en su mayoría provienen de la región geográfica del Medio Atrato que referencia la cuenca del río del mismo nombre.

El mapa $2^{8}$ muestra la trayectoria migratoria de los afrocolombianos desplazados de la región del Atrato Medio en el Departamento del Chocó en su búsqueda de reubicación y finalmente asentamiento en la Localidad de Suba, en el Distrito Capital de Bogotá.

7 En Bojayá, Chocó, los combates entre los paramilitares y la guerrilla de las Fuerzas Armadas Revolucionarias de Colombia (FARC) que se iniciaron en Vigía del Fuerte, Antioquia, margen oriental del Atrato y que luego se concentraron en Bellavista, Bojayá, Chocó, margen occidental del mismo río, dejaron como saldo la muerte violenta, en el interior de la iglesia de Bojayá, de entre 74 y II civiles, debido a la explosión de un cilindro bomba lanzado por miembros del bloque 58 de las farc el 2 de mayo de 2002. Los mapas que se presentan para ilustrar la información consignada en este artículo fueron adaptados de otros elaborados para el Proyecto Desplazamiento Forzado y Territorio: Interacciones y Transformaciones. 2010-2012. 


\section{Mapa 2}

Trayectorias migratorias de los desplazados reubicados en la localidad de Suba, Unidad de Planeación Zonal, UPZ, Tibabuyes

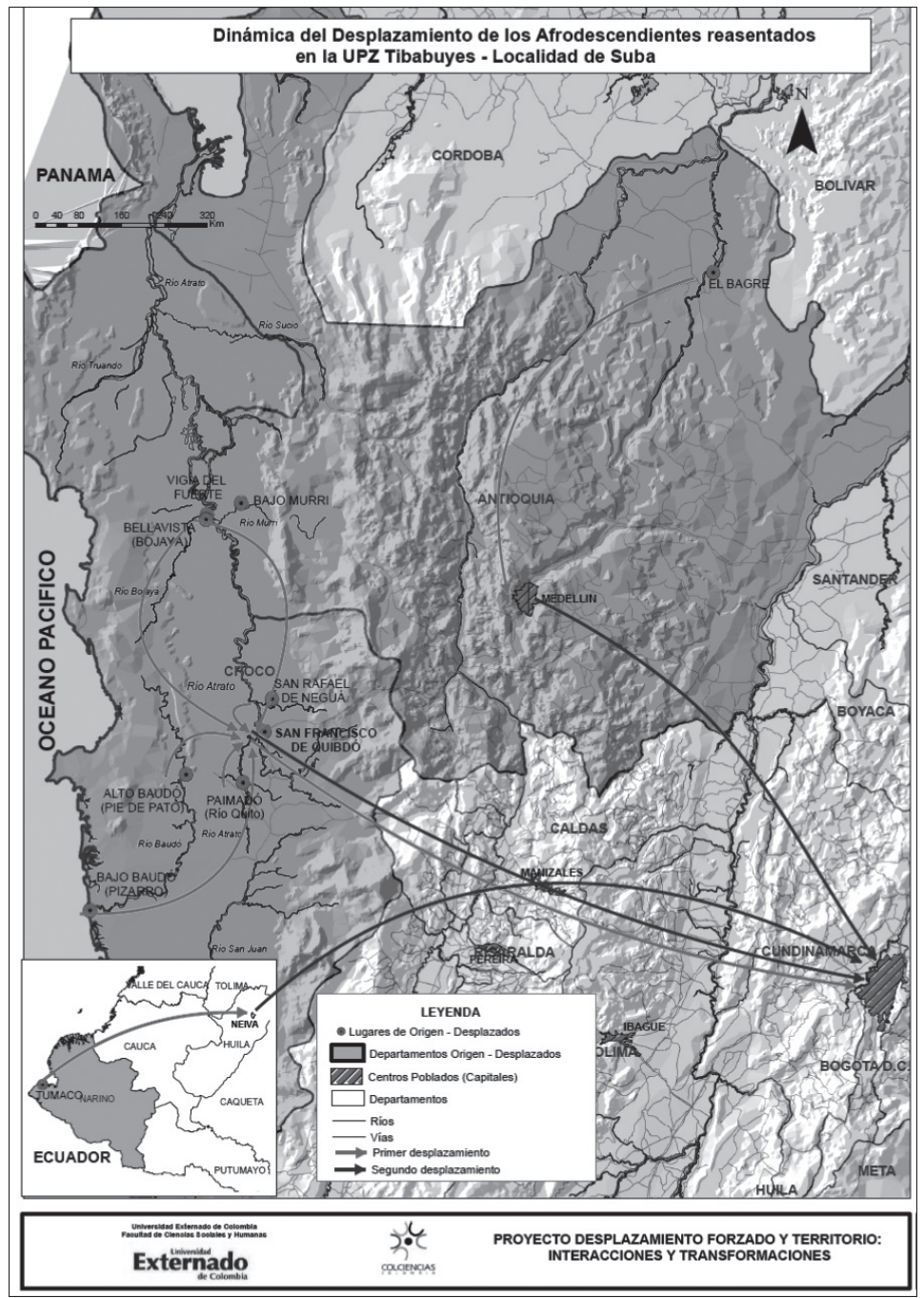

Fuente: Elaboración propia con datos del Sig-от del Instituto Geográfico Agustín Codazzi de Colombia (IGAC), adaptado de la cartografía del Proyecto Desplazamiento Forzado y Territorio: Interacciones y Transformaciones. 
De acuerdo con los resultados de las entrevistas, estas personas realizaban actividades productivas o tenían ocupaciones en el lugar de procedencia de acuerdo con la temporada climática y con las posibilidades ofrecidas por el medio biofísico. Una misma persona podía practicar la minería en una época del año y en otra la agricultura, esta última actividad ocupaba la mayor parte del tiempo de los entrevistados. Ocho de las quince personas se ocupaban de labores agrícolas y del cuidado de animales, cinco de ellas realizaban actividades de minería, dos se dedicaban a la piscicultura, una realizaba oficios varios y labores domésticas. Catorce de las personas entrevistadas fueron desplazadas forzadamente durante la década del 2000; el 2002 aparece como el momento en el cual la mayoría de las personas que conforman los grupos familiares de los entrevistados abandonaron su lugar de residencia. Este año corresponde a la fecha de los hechos de Bojayá donde murieron más de Ioo personas habitantes de las comunidades ribereñas del Atrato. La edad de los desplazados entrevistados oscila entre los 25 y los 49 años, con un promedio de 35 años; las personas entrevistadas poseen diverso grado de escolaridad: doce de ellas se encuentra entre el analfabetismo y la primaria completa, cuatro concluyeron la educación primaria, seis iniciaron la educación primaria y dos son analfabetas; de las tres restantes, una tiene educación secundaria incompleta y las dos últimas obtuvieron el título de bachiller. Estas condiciones no son obviamente las mejores para comenzar una buena vida en el medio urbano.

La trayectoria migratoria a Bogotá incluye generalmente una etapa intermedia en Quibdó, la capital del Departamento del Chocó, y/o Medellín, la capital del Departamento de Antioquia."Como no hay opciones laborales, en Quibdó éramos sostenidos por un familiar" (afirmó Flor, 32 años). Debido al desempleo la vida se tornaba difícil y no se suplían las necesidades básicas. Así, en un primer desplazamiento, llegaron donde un familiar, allí algunos fueron perseguidos, lo que los obligó a un segundo desplazamiento, hacia Bogotá, o hacia Medellín y después a Bogotá.

Los migrantes acuden al apoyo de la familia extensa: "Por mi hermano y los amigos. Primero me vine yo solo, después al tiempo me traje la familia. Cuando llegué acá [a Santa Rita, Suba], había personas que ya conocíamos, hay mucho paisanos de allá" ( Javier ${ }^{9}, 38$ años); Los miembros de estas redes son como eslabones que los acogen hasta el momento en que logran establecer relaciones laborales capaces de hacer posible independizarse, así sea de manera precaria. En la ciudad la familia extensa es el principal apoyo económico y emocional. Es importante resaltar que 
cuando el afrocolombiano desplazado logra tener independencia y suplir sus necesidades básicas, esta acción de apoyo para el hospedaje y hospitalidad es replicada con otro familiar, amigo o paisano que llegue a necesitarlo. Así se va construyendo una cadena de solidaridad con el recién llegado.

La mayoría de las personas entrevistadas (I4) se desplazó en forma individual, si bien el suceso violento afectó al grupo familiar. La llegada al barrio donde ahora se ubican (Santa Rita, Santa Cecilia, San Pedro y Lisboa) se realizó principalmente entre 2005 y 2008. Todos los participantes en la investigación llegaron a Tibabuyes gracias al apoyo de otras personas habitantes del sector. Algunos venían del barrio Rincón de Suba, otro sector de la localidad. La búsqueda de arrendamientos más económicos fue frecuentemente mencionada como motivo para el cambio de lugar de residencia.

\section{El reasentamiento en Tibabuyes}

Tibabuyes es un escenario donde se presentan grandes contrastes sociales. Allí confluyen desplazados, familias inmigrantes de diversos departamentos del país ${ }^{10}$ llegadas a la localidad desde el inicio de estos barrios, desmovilizados de grupos armados, recicladores de materiales de desecho. En los barrios San Pedro, Berlín, Lisboa, Santa Cecilia, Villa Cindy y Santa Rita, lugar de este estudio, se hace evidente la precariedad y fragilidad en las condiciones de vida de los habitantes, se percibe la contaminación ambiental asociada a la proximidad de los ríos Bogotá y Juan Amarillo. La mayoría de las calles son estrechas y sin pavimentar, con muchos lotes sin construir que se utilizan como botaderos de basura y sitios de reciclaje. Estos barrios son resultado de un proceso reciente de expansión urbana generada en la localidad de Suba en los años 70 y 80 del siglo xx. Desde esta época se construyeron casas que se levantaron por autoconstrucción, sin planeación previa en el emplazamiento y para la dotación de servicios públicos, que sucesivamente se fueron convirtiendo en barrios, manzanas y vías en proceso de legalización.

El mapa 3 muestra el área de reasentamiento de los desplazados en el sector urbano de Tibabuyes, la infraestructura urbana y la proximidad de los ríos Bogotá y

10 La mayor parte de los padres de los antiguos residentes de Tibabuyes migraron a Bogotá desde los departamentos de Boyacá y Santander en la segunda mitad de la década de los cincuenta y la primera mitad de la década de los años 60 del siglo xx (Notas de campo de la aplicación de la encuesta con los antiguos residentes). 
Juan Amarillo que actualmente constituyen factor de riesgo de inundación. También da cuenta de referentes de apropiación del barrio y de la ciudad de Bogotá por parte de la población desplazada en proceso de reasentamiento.

\section{Mapa 3}

Área de reasentamiento de los desplazados en Tibabuyes

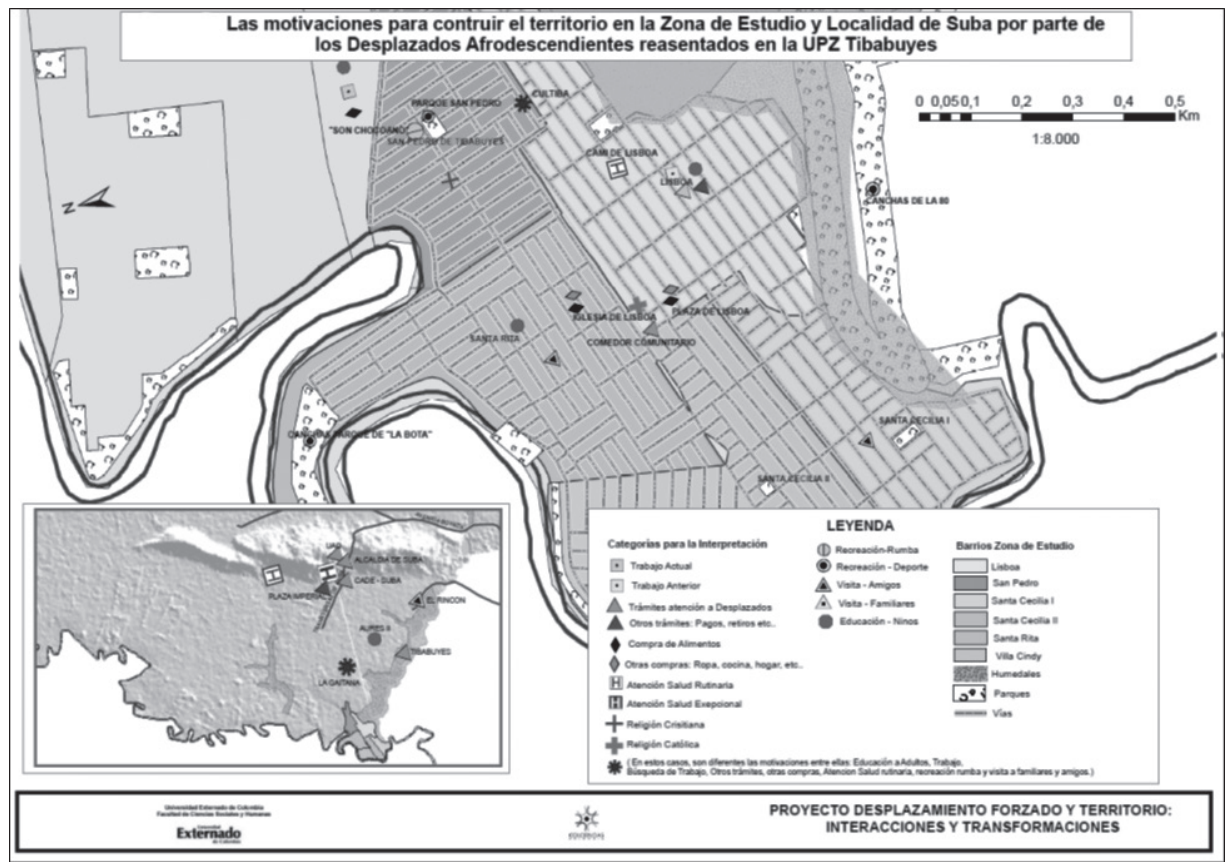

Fuente: Elaboración propia con datos del SIG-OT del Instituto Geográfico Agustín Codazzi de Colombia (IGAC), adaptado de la cartografía del Proyecto Desplazamiento Forzado y Territorio: Interacciones y Transformaciones. 


\section{La vida de los desplazados en Tibabuyes}

De acuerdo con las entrevistas en profundidad realizadas, dos aspectos merecen ser destacados: la precariedad de la vivienda y las dificultades para conseguir empleo. ${ }^{11}$ Las casas de los entrevistados en general presentan condiciones inadecuadas, con problemas de humedad, o no constituyen alojamientos en sí mismos, sino que son otro tipo de instalaciones (como bodegas o parqueaderos), que son adecuadas someramente por los propietarios para ser alquiladas a los desplazados. Cabe resaltar que a pesar de la limitada habitabilidad de las viviendas los arriendos son tan elevados como los de viviendas y apartamentos en mejores condiciones ubicados en el mismo sector. También se pudo identificar la existencia de pactos entre vecinos para no alquilar a desplazados afrocolombianos u oriundos de la costa Atlántica. Lograr ser admitido como inquilino supone casi siempre una recomendación de algún conocido del propietario, éste justifica su negativa a arrendar por la presencia de muchos niños y el ruido que se asocia a las costumbres de la población afrodescendiente.

Los hombres entrevistados se hallan empleados como obreros de construcción o celadores. Las mujeres en cambio trabajan en el servicio doméstico, o también a veces en construcción, pero estos empleos son esporádicos y las mujeres los viven difícilmente. Varias de las entrevistadas manifestaron que sólo las contrataban para realizar labores de aseo extraordinarias, por el mismo salario de una jornada de trabajo normal, además de ser víctimas de discriminación en su lugar de trabajo.

Otra opción para conseguir ingresos entre los afrocolombianos entrevistados era esperar recibir el subsidio para proyecto productivo que otorgaba la Agencia Presidencial para la Acción Social dentro del programa de estabilización de población desplazada. Otros negocios han sido ofrecer servicios de lavadora a domicilio, venta de mercancía para vender a crédito, entre otros. Esta forma de trabajo no logra producir como ingreso un salario mínimo mensual; es esencialmente informal, inestable y no provee opciones para contar con un esquema completo de seguridad social. Así, la situación económica los obliga a vivir de los subsidios monetarios como opción de apoyo, también del comedor comunitario y de otras modalidades de subsidio ofrecidas por diversas organizaciones no gubernamentales y por la Iglesia Católica. Las precarias condiciones laborales y las acciones asistencialistas se combinan para lograr la supervivencia en condiciones limitadas y sin muchas posibilidades de

11 De las personas entrevistadas el 93\% vive actualmente en alojamiento de alquiler, sólo una de ellas posee casa propia. El $33 \%$ de las personas entrevistadas se encontraban desempleadas y la mayoría de los empleos que obtienen las mujeres son temporales. 
romper el círculo vicioso de marginalidad y pobreza en el que se encuentran. Es frecuente que cambien de domicilio, pero este cambio implica moverse sólo unas pocas cuadras y seguir en últimas en las mismas condiciones.

Es usual que los afrocolombianos se reúnan las tardes de domingo a jugar fútbol con sus paisanos, los hombres juegan mientras las mujeres les hacen barra; ocasionalmente se juega bingo en la calle, entre semana, y se baila los fines de semana en el Son Chocoano, la discoteca del barrio San Pedro. La mayoría ha establecido relaciones con personas externas a la comunidad afrocolombiana. Con los vecinos se tienen relaciones de respeto y cordialidad, sin embargo, no se establecen relaciones cercanas con ellos ni se logra mayor nivel de confianza, si bien las personas afro sostienen contactos que les indican el reconocimiento hacia ellos.

\section{La extensión del territorio de los desplazados afrocolombianos}

Los ejercicios de georreferenciación y de cartografía social mostraron un conjunto de lugares frecuentados muy limitado, especialmente por parte de las mujeres. Un primer núcleo lo constituyen los espacios de la vida cotidiana (la iglesia, la plaza de mercado y el comedor comunitario de Lisboa, la discoteca de San Pedro, las canchas de fútbol del parque de La Bota y de la 8o, la sede de la ong Cultiba, el billar). El centro de la localidad de Suba se visita con menos frecuencia, esencialmente para adelantar trámites relacionados con la atención a la población desplazada en la $\mathrm{UAO}^{12}$. Se aprovecha este trayecto dentro del territorio donde se ubican las agencias estatales para visitar algún centro comercial, pero no se compra nada allí. Los ingresos son insuficientes. Las compras de ropa y calzado se realizan en el centro de la ciudad, en el sector de San Victorino, reputado por amplia oferta y bajos precios, una o dos veces al año. Los grandes parques metropolitanos se visitan muy poco y los alrededores de la ciudad son prácticamente desconocidos.

Los hombres tienen un territorio más amplio; los trabajos de celaduría y construcción los llevan a conocer diversos sectores de la ciudad, aun cuando por lo general los trabajos no los llevan demasiado lejos de Tibabuyes. En algunos casos estos trabajos pueden llevarlos a municipios cercanos dentro de la Sabana de Bogotá.

12

Unidad de Atención y Orientación del Programa para desplazados de la Agencia Presidencial para la Acción Social. 
Una calle del barrio Santa Rita donde habitan, que conduce al parque de La Bota, se conoce en el sector como la "calle de los niches ${ }^{13}$ ", sobre ella se encuentra el billar, así como dos o tres establecimientos públicos en los que se bebe cerveza y se juega al dominó. Son particularmente visibles y su presencia ha terminado por caracterizar el lugar. Dussault (20II) señala que uno de los objetivos de las estrategias de apropiación del espacio es garantizar la legitimación de su uso autónomo, al tiempo que se busca mantener una presencia valorizante en el espacio y por consiguiente un lugar reconocido en la sociedad.

Desde esta perspectiva parcial, el proceso de construcción de territorio ha sido exitoso, pero también es posible hacer una lectura diferente. La denominada "calle de los niches" para los habitantes no afro es el "malecón" de los afro. El espacio de los barrios habitados por los desplazados afrocolombianos ha sido apropiado como una metáfora del territorio de origen. Esta estrategia permite, al menos en parte, recuperar algo de lo que se han perdido. De acuerdo con la presentación que Rivera (2010) hace de las ideas de Blumenberg, la metáfora puede entenderse como una estrategia del ser humano, quien consigue sobrevivir porque, lejos de establecer relaciones inmediatas con la realidad, se aproxima a ésta de modo indirecto, mediato, selectivo. Así se logra despotenciar el mundo hostil, dotarlo de significación y hacerlo más familiar o seguro.

En las entrevistas aparecieron de manera muy fuerte algunos de los elementos que más se extrañan del territorio de origen: el río y sus posibilidades lúdicas, las relaciones de vecindad y de solidaridad con la familia extensa y la amplia disponibilidad de recursos autoapropiados, que permitirían llevar una vida sólo parcialmente inmersa en el sistema monetario. Las pequeñas cantidades pesadas y medidas con precisión, que sólo pueden ser adquiridas con un dinero no siempre disponible, hacen añorar fuertemente el racimo de plátanos o el pescado entero que se podían obtener directamente. El pago regular del arriendo y de los servicios públicos es una carga particularmente pesada cuando los ingresos son inestables e insuficientes. La falta de vivienda propia afecta de manera central la estabilidad de los desplazados afrocolombianos y es uno de los factores que hace difícil sentirse habitante pleno de la ciudad:

Si yo acá [en Bogotá] tuviera una propiedad, me sentiría la mujer más feliz del mundo. Que tuviera no, pues, una casa, sino que tuviera mi ranchito, un ranchito

13 Término equivalente a negro u oriundo de Buenaventura, el principal puerto sobre el Pacífico colombiano. 


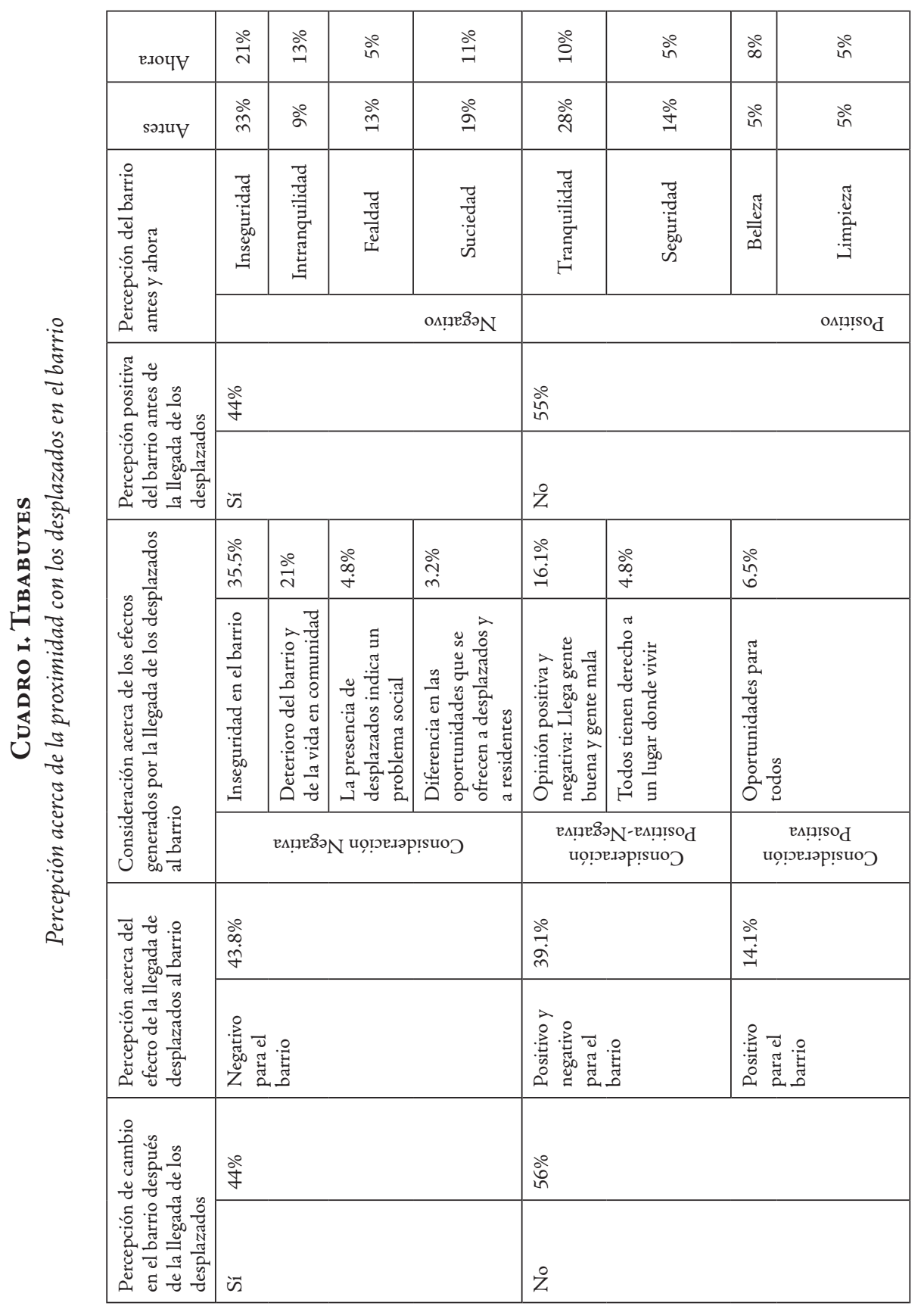

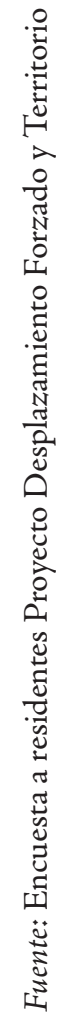


donde pudiera echar sueño con mis hijos, sin tener que pensar'ah, se me va a llegar el día del arriendo', entonces si yo tuviera eso, yo viviría feliz, porque para lo demás, trabajaría, trabajaría duro (Gina, 34 años).

\section{La visión de los antiguos residentes}

La encuesta fue el principal instrumento para recoger la visión de los residentes sobre las consecuencias del proceso de reasentamiento de los desplazados. Con ellos no se hicieron entrevistas, pero sí se tomaron notas de las conversaciones sostenidas durante la aplicación de la encuesta. El cuadro i resume algunos de los principales resultados.

El primer elemento por destacar de acuerdo con el cuadro I es que un poco más de la mitad de los encuestados estima que la llegada de los desplazados no ocasiona cambios significativos en el barrio. El desarrollo del trabajo mostró que en realidad no existe por lo general una relación causal directa atribuida por los antiguos residentes, en la medida que para éstos la ocurrencia de transformaciones substanciales en su sector de habitación no se relaciona con la llegada de desplazados o desarraigados.

De los encuestados, el $44 \%$ estima que la llegada de los desplazados trae sólo consecuencias negativas para el barrio, como el aumento de la inseguridad y el deterioro del barrio; sólo un 3.2\% de los encuestados menciona problemas generados por oportunidades diferentes ofrecidas por el Estado y las organizaciones no gubernamentales a desplazados y a personas ya residentes en el sector. No obstante, en las conversaciones que acompañaron las entrevistas, muchos antiguos residentes manifestaron que era injusto que los desplazados recibieran lo que para ellos es difícil de acceder, es decir, que los residentes antiguos tienen menos facilidades de acceso a programas de reducción de la pobreza. Reconocen que los desplazados requieren una atención especial, pero ello no debería impedir que las ayudas también beneficien a personas en condiciones similares de precariedad. Con mucha frecuencia los entrevistados manifestaron reserva y desconfianza respecto a la autenticidad de la condición de desplazado de sus vecinos. Para muchos de ellos, entre los desplazados por la violencia se camuflan muchos que vinieron a la ciudad en busca de mejores opciones de vida. Llama la atención que ante un fenómeno multicausal como la migración forzada por la violencia, predominen visiones dicotómicas respecto a quien es realmente un auténtico desplazado, sin ningún tipo de matiz entre estas dos posiciones extremas. 
Una lectura de los resultados a la luz de la conceptualización de Mercier (2009), llevaría a afirmar que Tibabuyes es más un lugar que a un territorio en cuanto los desplazados afrocolombianos más que ejercer algún tipo de poder, apenas se acomodan a las condiciones impuestas por otros: el Estado, el mercado laboral, los arrendadores. Si se retoma la conceptualización de Debarbieux (2003), del territorio como una combinación de recursos materiales y simbólicos capaces de estructurar las condiciones prácticas de la existencia de un individuo o de un grupo social y de aportar en sentido inverso al individuo o al grupo social sobre su propia identidad, se podría decir que solo de una manera muy parcial Tibabuyes es un territorio para los afrocolombianos desplazados. Ya existe un arraigo, pero muy pocos de los elementos existentes en la zona y en Bogotá han adquirido la condición de recurso para ellos.

\section{Los campesinos-indígenas del Alto Naya reasentados en el municipio de Timbío}

Este estudio de caso analiza el proceso de reasentamiento en la finca La Laguna, en el municipio de Timbío, en el Departamento del Cauca (ver mapa 4), de un grupo de familias campesino-indígenas ${ }^{14}$ desplazadas por la violencia de la región del Alto Naya, ubicada entre los Departamentos de Cauca y el Valle del Cauca (ver mapa 5). La masacre del Alto Naya, perpetrada por paramilitares durante la Semana Santa del 20oI, es uno de los episodios del conflicto armado colombiano que ha recibido más atención tanto en Colombia, como fuera de ella.

El mapa 4. Muestra el predio La Laguna, donde se reubicaron los campesinos-indígenas de la comunidad desplazada de la región del Alto Naya entre las veredas San Pedrito y las Guacas dentro del territorio del municipio de Timbío. En la finca La Laguna habita la comunidad de indígenas de origen Nasa que conforman actualmente el Cabildo Kitek Kiwe como ya se explicó. Allí han ubicado un lugar como monumento a las víctimas, el cementerio de la comunidad, el centro educativo Elías Trochez, líder asesinado por los paramilitares, la casa Nasa, emblema del asentamiento y el lugar sagrado donde reverencian a su panteón de seres sobrenaturales.

14 La calificación de campesino-indígena refleja el proceso de re-etnización que la comunidad ha venido adelantando tras el desplazamiento forzado. 


\section{MAPA 4}

Predio La Laguna en Timbio (Cauca). Lugar de reasentamiento de la comunidad desplazada del Alto Naya

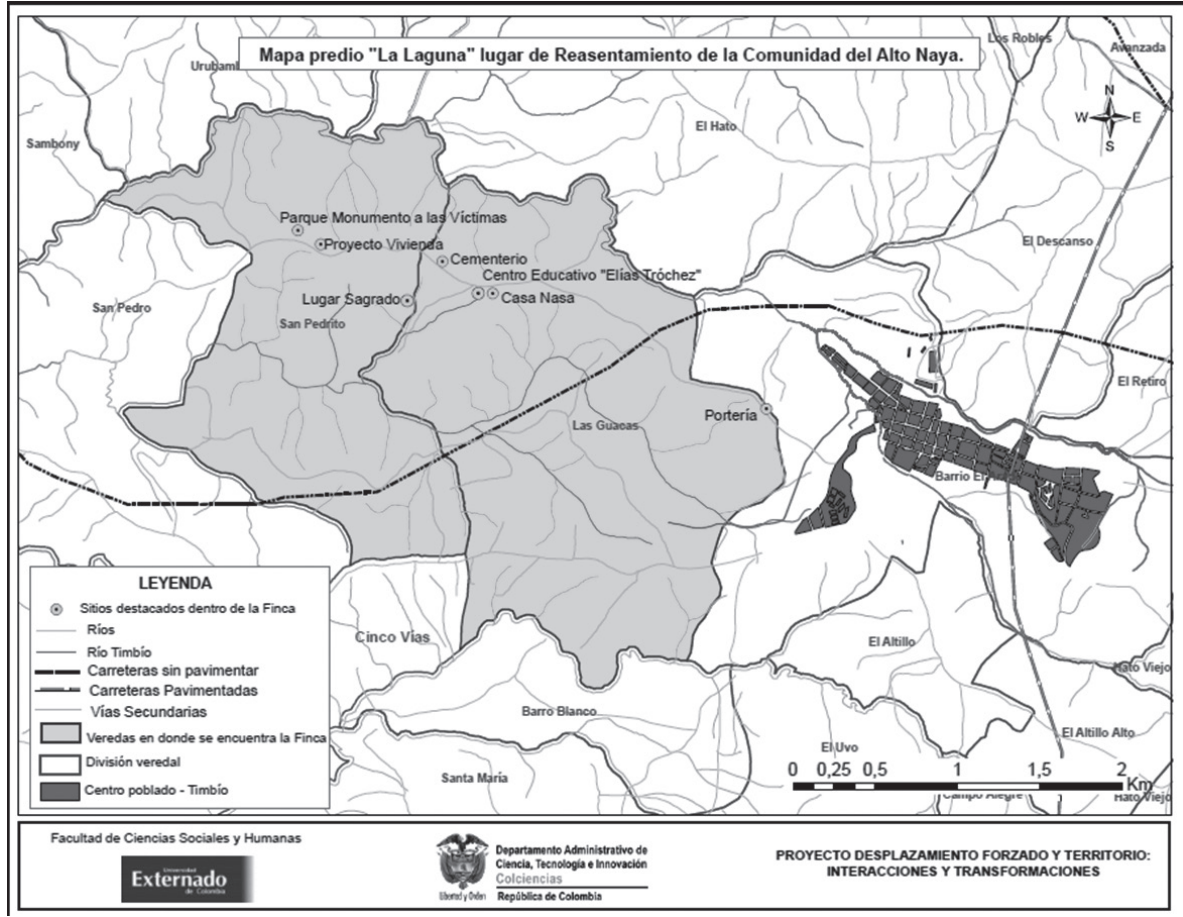

Fuente: Elaboración propia con datos del SIG-от del Instituto Geográfico Agustín Codazzi de Colombia (IGAC), adaptado de la cartografía del Proyecto Desplazamiento Forzado y Territorio: Interacciones y Transformaciones.

El mapa 5 muestra el contexto regional del Alto Naya donde se ubican lugares de referencia física y simbólica para la población como el Cerro Naya, donde además nace el rio Naya que otorga el nombre a toda la región; el sitio el Playón y la Playa desde donde parten los caminos para salir de la apartada región montañosa donde habitaban hacia los centro rurales El Ceral y La Meseta. Se ubican igualmente los centros urbanos más importantes para el comercio como Cali, capital del Departamento del Valle y el municipio de Jamundí, y el municipio de Santander de Quilichao en el Departamento del Cauca. 


\section{Mapa 5}

Contexto regional de la región del Alto Naya

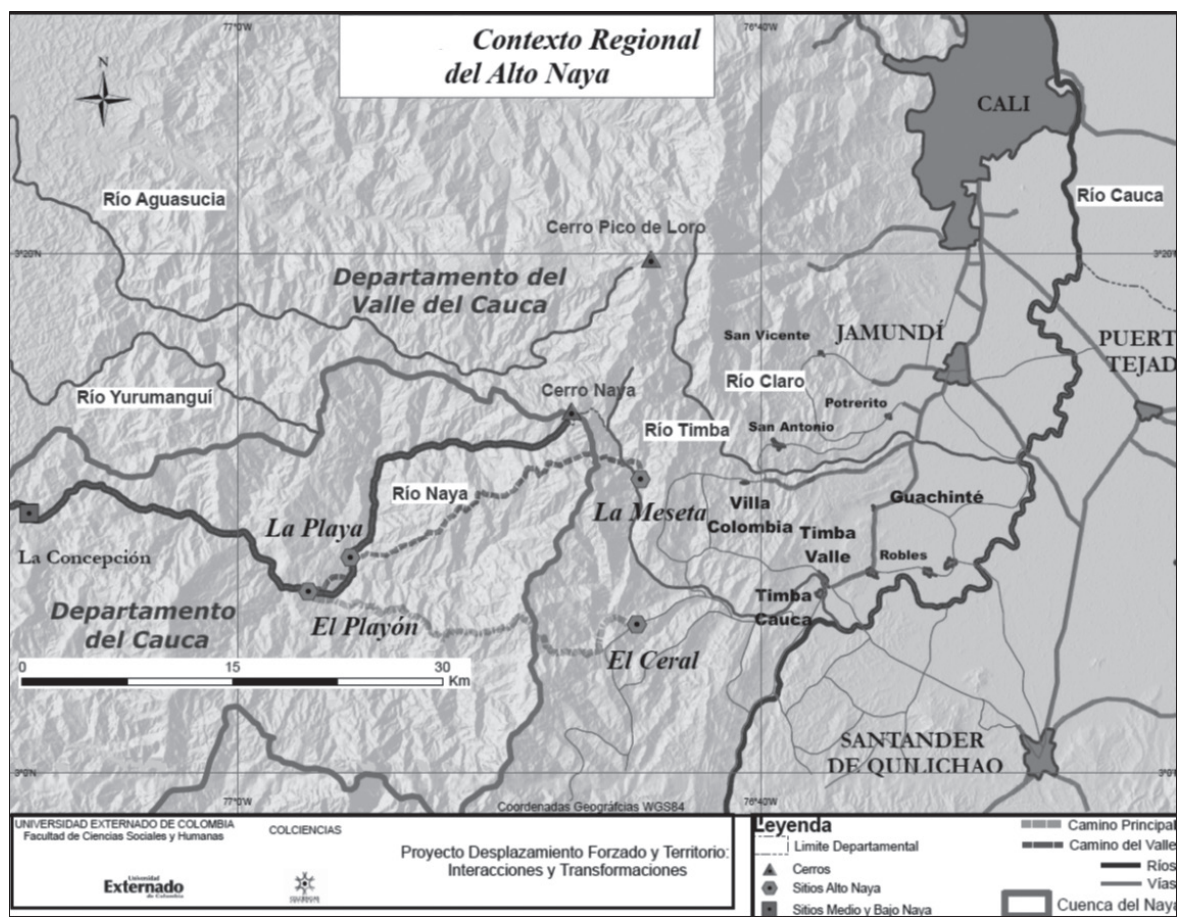

Fuente: Elaboración propia con datos del Sig-от del Instituto Geográfico Agustín Codazzi de Colombia (IGAC), adaptado de la cartografía del Proyecto Desplazamiento Forzado y Territorio: Interacciones y Transformaciones.

\section{Colonización del Alto Naya y desplazamiento forzado}

La región del Naya se encuentra en el Pacífico central colombiano. La zona se caracteriza por muy fuertes pendientes y elevados niveles de precipitación. Las condiciones del Alto Naya no hacen muy fácil el proceso de ocupación por parte de un grupo humano. Las altas pendientes y la limitada capacidad productiva de los suelos, sumadas a la falta de vías de comunicación hacen muy difícil llevar al mercado productos lícitos. No obstante, la abundancia de tierras y las condiciones 
climáticas permiten obtener los recursos alimentarios básicos y vivir en condiciones de gran autonomía y pocos intercambios monetarios con el mundo exterior.

Los primeros asentamientos en el Naya fueron los enclaves mineros explotados mediante esclavos negros. Tras la abolición de la esclavitud en I85I, los negros se dispersaron por toda la región y establecieron poblados en la parte baja y media del río Naya que persisten en la actualidad. La parte alta de la cuenca del Naya se fue poblando con la llegada de indígenas Nasa (nombrados también como indígenas paeces) a principios de los años 50 del siglo pasado y por un número significativo de familias campesinas mestizas procedentes de otras zonas del país. La violencia bipartidista y la adversa estructura de tenencia de la tierra llevaron a indígenas y campesinos a colonizar en condiciones difíciles un entorno agreste, prácticamente despoblado (García y Jaramillo, 2008).

El poblamiento del Alto Naya se dio de manera paulatina; familias de campesinos mestizos e indígenas fueron llegando gradualmente, gracias a los lazos de parentesco y amistad. La economía se basaba esencialmente en cultivos de pancoger, caza y pesca. Pocos bienes debían adquirirse en el mercado y el cultivo del cacao, la explotación de oro de aluvión y el trabajo asalariado ocasional por fuera de la región, lograban proveer el poco dinero necesario.

Las viviendas del Alto Naya estaban bastante dispersas. Era normal tener un vecino a 15 minutos de camino y algunos otros a dos horas. Las relaciones entre ellos eran de cooperación, ya que frecuentemente se unían para construir los caminos, las escuelas y, en general, para hacer frente a las necesidades de la comunidad. En palabras de María, 65 años, "el respeto que había de uno a otro era muy sagrado", y todo se compartía, tanto el trabajo como el fruto de éste en el intercambio de alimentos entre vecinos. Gracias al trabajo comunitario se construían y mantenían los caminos, única vía posible de comunicación con el mundo exterior y se construyeron las dos escuelas de las veredas La Playa y El Playón, los dos principales asentamientos de la región. Las juntas de acción comunal fueron los primeros espacios de interlocución con el Estado, desde los cuales se ha buscado gestionar servicios públicos como la educación y la salud.

La situación cambió radicalmente con la introducción de los cultivos ilícitos. Se dice que la coca llegó en los años 70 cuando los indígenas apenas la utilizaban para el uso diario tradicional de mascar y trabajar. Esto cambió hacia mediados de la década de los 70, cuando entraron al Alto Naya personas distintas a los primeros habitantes. Los recién llegados ofrecieron altos precios por las hojas de coca y los indígenas empezaron a cultivarla para venderla a los actores armados y a grupos de narcotraficantes. La coca empezó a generar otro tipo de empleos en la zona: comer- 
cialización de víveres con las personas que venían a comprarla y luego transporte de la hoja fuera de la región. Los cultivos fueron extendiéndose, pasando de unas pocas matas a 405 hectáreas por grupo familiar. La coca traería nuevos pobladores de diversa índole: tanto las personas que se encargaban del procesamiento de la hoja, como grupos armados al margen de la ley. A principios de los años 70 llegó el grupo guerrillero M-ı́, después las Fuerzas Armadas Revolucionarias de Colombia, FARC, y el Ejército de Liberación Nacional, enN, a mediados de la misma década, y finalmente los paramilitares a finales de los 90. Todos estos grupos han reconocido la importancia estratégica, tanto militar como económica de la región del Naya.

En este contexto de enfrentamiento de grupos armados, de comercio de productos ilícitos, surge el cabildo indígena en los años 80 como una forma de organización que correspondía con la raigambre de la tradición política y cultural de los habitantes Nasa. Así se crea en 1993 el Cabildo de La Playa. El Cabildo tenía como propósito fundamental proteger el territorio del Naya, controlar la participación de los indígenas en el cultivo de la coca y frenar el deterioro del medio ambiente, además de ser una instancia que garantizaba el trabajo comunitario de los habitantes de la zona del Alto Naya. Lamentablemente estos procesos organizativos fueron y siguen siendo irrespetados por los grupos armados, como lo muestra el asesinato del primer gobernador Elías Tróchez, por el eln en el año 2000 (ILSA, 2006).

El Naya se convirtió en un lugar de acciones de guerra, la guerrilla del ens la utilizó como fortín aislado para mantener ocultas a víctimas de secuestros masivos cometidos en 1999 y 2000. ${ }^{15}$ Aunque era claro que los pobladores del Naya eran víctima de las acciones del grupo guerrillero, la situación fue percibida con recelo tanto por las fuerzas armadas del Estado, como por los grupos paramilitares -Bloque Farallones de Cali y Bloque Calima de las AUC- que entraron a la región a comienzos del año 2000. En un lapso de seis meses, hasta comienzos del 200I, fueron asesinadas o desaparecidas cerca de 400 personas, en su mayoría recolectores de hoja de coca o "raspachines" (García y Jaramillo, 2008), lo cual generó un primer desplazamiento. El ejército hizo presencia con tropas del Batallón Pichincha hacia el final del año, lo que permitió normalizar la situación y facilitar el retorno de la población (AFRODES et al., 2002). No obstante, la masacre del Naya se produjo

15 Los concejales de Jamundí fueron secuestrados durante más de un año, paseados a la vista de los habitantes del Alto Naya y obligados a trabajos forzados como escarnio por conductas corruptas que les fueron imputadas. Otros secuestros ampliamente recordados son los de la iglesia de La María en Cali y el del kilómetro i8 de la vía Cali-Buenaventura (García y Jaramillo, 2008). 
durante la Semana Santa del 20or y ocasionó más de cincuenta y cuatro muertes y más de seiscientas personas desplazadas (Jimeno et al., 20II).

\section{Éxodo y reasentamiento}

Los desplazados del Alto Naya tuvieron que refugiarse transitoriamente en diversos lugares, especialmente en Timba, donde contaron con la ayuda del párroco, hasta llegar a la plaza de toros de Santander de Quilichao; allí debieron permanecer en un estado de hacinamiento crítico durante tres años. En el año 2002, las comunidades desplazadas crean asocaidena, la Asociación Agropecuaria de Campesinos e Indígenas Desplazados del Alto Naya, que al año siguiente interpone una acción de tutela solicitando la reubicación de las familias desplazadas. Esta acción se resuelve favorablemente y el Instituto Colombiano de Desarrollo Rural, InCoder compra el predio La Laguna, situado en el municipio de Timbío, el cual es entregado a la comunidad el 4 de marzo de 2004 (Jimeno et al., 20II).

La subsistencia de la comunidad de desplazados fue en principio difícil. La venta de la madera existente en el predio proveyó recursos durante un tiempo, pero diversos proyectos agrícolas como la siembra de repollo fracasaron; otras iniciativas, como el proyecto de ganadería no dieron los resultados esperados. A diferencia del Alto Naya, el predio La Laguna se encuentra situado a unos 1800 metros de altitud, con unos niveles de precipitación considerablemente menores. El crecimiento de las plantas es mucho menos rápido y la comunidad de campesinos-indígenas desplazados extraña el tipo de agricultura que se practicaba en su lugar de procedencia: "Digamos el maíz en el Naya, en tres meses, usted ya empezaba a ver los primeros choclos, acá no, [se requieren] 6 meses, 8 meses" (Henry, 59 años); "allá sí, usted sin fertilizantes, sin control de plagas, usted puede cultivar de pronto los alimentos, pues aquí toca que meterle más plata porque tiene que todo comprarlo para poder cultivar, entonces de pronto sí, las tierras de allá son más fértiles" (Pedro, 58 años).

La Laguna fue recibida por los miembros de la Asociación de Desplazados del Naya, ASOCAIDENA como propiedad colectiva y allí se constituyó el Cabildo indígena Kitek Kiwe. Luego de 2 años de reasentamiento en la finca, decidieron parcelarla y distribuir 3,5 hectáreas de tierra por familia. Esta extensión es insuficiente para 
el adecuado sostenimiento de la población actual ${ }^{16}$. La vivienda fue precaria en principio pero la comunidad se benefició con un proyecto de vivienda para dotar a algunas familias de un espacio para habitar, aun cuando las casas no cuentan todavía con agua potable.

Los sentimientos de pertenencia florecen cuando los miembros de la comunidad han constituido una identidad articulada con la apropiación de su nuevo espacio. Para los jóvenes, el futuro se encuentra en Timbío. Por esto han empezado a establecer planes que les permitan fortalecer el nuevo territorio: crear un acueducto, instalar los servicios de energía y alcantarillado, habitar de manera digna las viviendas construidas en la finca por parte del Estado. También tienen proyectos educativos, como la creación de una universidad indígena en Timbío, y dos proyectos más, que pueden transformar radicalmente su actual forma de vida: la constitución de la Finca la Laguna como Resguardo y la creación del proyecto turístico "Parque Monumento a la Memoria".

La mirada de los mayores es totalmente diferente porque su evocación continúa estando en el Naya y en el retorno. A pesar de la permanencia de las circunstancias adversas en el territorio del Naya, ellos mantienen la esperanza, la añoranza y la certeza de que algún día van a regresar y si ellos mismos no lo logran, esperan que su descendencia sí lo haga. A los mayores los llaman sus raíces, "sus ombligos enterrados en el Alto Naya" y una relación única de territorialidad: "Preferiría más estar allá que acá por mi ombligo... estar en el Naya, en Loma Linda, porque allá fue que crecimos, y de allá nos vinimos pa acá... allá ya vivíamos así como se ve el mapa, se veían veredas así lejitos y los vecinos de lejitos y, pá qué, uno en el Naya vivía muy sabroso con la familia" (Jaime, 60 años).

Los mayores son conscientes de que los niños y los adolescentes que han crecido en Timbío difícilmente se adaptarían a las condiciones del Alto Naya, en donde no tendrían acceso a las modernas tecnologías de las comunicaciones y a las posibilidades que ofrece una ciudad como Popayán. que una familia tenga unos ingresos aceptables. En la zona correspondiente a La Laguna se estima que la extensión mínima de la UAF debe estar en comprendida entre 4 y 6 hectáreas (Resolución 04I/1996 del INCORA). 


\section{Organización y reetnización}

Si bien, la adjudicación del predio La Laguna es un logro en la lucha por sus derechos como víctimas y ciudadanos, el proceso de lograr un nuevo proyecto de vida implicó primero consolidar la organización ASOCAIDENA y conformar el Cabildo Nasa Kitek Kiwe en el año 2005, como organización que los encaminara a consolidar un proyecto de vida propio y autónomo. Como mencionan los comuneros, "el Cabildo permite el fortalecimiento de la estructura social interna y el establecimiento de una organización autónoma" (Henry, 59 años). La Asociación de Cabildos Indígenas del Norte del Cauca, ACin, y el Consejo Regional Indígena del Cauca, CRIC, se solidarizaron con la causa del Alto Naya, reconociendo a la población en su origen indígena. Estas acciones promovieron paulatinamente un proceso de reetnización o reindigenización entre la comunidad de indígenas campesinos Nasa a través del cual obtuvieron el reconocimiento como etnia y pasaron a formar parte de los cabildos, mientras rescataban elementos de su identidad indígena y facilitaban que ASOCAIDENA comenzara a ser parte del movimiento indígena caucano.

La comunidad reasentada en la finca La Laguna ha estructurado su proceso organizativo a través de dos ejes principales: el fortalecimiento de la identidad indígena Nasa y la estrecha relación con diferentes entes del gobierno y con diversas ong e instituciones internacionales:

Ese proceso organizativo comienza por la necesidad, porque necesitamos tener una identidad o cómo hacer valer esos derechos y las relaciones con las instituciones, pues yo creo que en esa parte nosotros hemos sido una comunidad indígena que nos hemos hecho, tal vez diría yo, respetar, porque si uno no va con claridad, claramente, ellos no... si usted va por cualquier cosa, le dan otra cosa que usted no necesita" (Estela, 42 años).

La cosmovisión Nasa les restituyó el valor y el sentido de la relación establecida con el territorio, tanto del Alto Naya como de Timbío. Esta adopción de la cosmovisión como indígenas, emprendida por una comunidad, busca su pervivencia como grupo a través de un modelo educativo y un sistema de salud propios. En este marco dice Mercedes, 29 años, "Aquí me encontré con una gran sorpresa... porque yo no sabía qué era, o sea yo decía ‘'soy india, soy mestiza, qué soy?’ y al estar aquí recuperé mi identidad... el indio sin tierra no es indio, entonces lo primero fue la tierra, luego la identidad..." 


\section{Población residente}

La población residente del municipio de Timbío que participó en la investigación respondiendo la encuesta, corresponde a un total de 62 personas; éstas se encuentran en un rango de edad entre 17 y 78 años, con un promedio de 43 años; $63 \%$ de las 62 personas son mujeres, $37 \%$ son hombres. Los residentes poseen distintos niveles de escolaridad: el $29 \%$ cuenta con primaria completa, el I7\% tiene educación secundaria completa, el I2.9\% no ha terminado sus estudios de primaria, el II.3\% no ha terminado sus estudios de secundaria y el 9.7\% no cuenta con ningún nivel de escolaridad, 9.7\% cuenta con educación técnica y 9.7\% ha accedido a estudios universitarios.

\section{La visión de los antiguos residentes}

Las actitudes de los antiguos residentes ante la llegada de la comunidad de desplazados fueron diversas. En la administración municipal primó la desconfianza, mientras que los campesinos de las veredas circunvecinas fueron solidarios desde un principio:

Los vecinos sí nos recibieron bien pá qué. Cuando llegaron a apoyarnos con semillas fue una cosa muy bonita, bueno aquí se da esto, lo otro y llegaban con semillas; las primeras semillas de plátano, yuca, maíz, fríjol, que llegaron aquí fue por parte de ellos, de los campesinos de aquí, vecinos, nos traían eso a regalar para que nosotros empezáramos a sembrar comida, porque aquí no había comida, en esta finca" (Henry, 59 años).

La solidaridad brindada por los vecinos no solo fue un gesto que impulsó relaciones de cooperación entre las dos comunidades. Pronto los comuneros de La Laguna vincularon a los campesinos vecinos en proyectos que les permitieran a ambos grupos mejorar su calidad de vida, realizaron reuniones de integración e intercambio de saberes, y a través de esta relación los vecinos fueron apropiando conocimientos sobre la defensa de los derechos humanos que la comunidad del Alto Naya había ido aprendiendo a lo largo del proceso para reorganizar su vida. En dos proyectos distintos el Cabildo Kitek Kiwe vinculó a unas I20 familias campesinas de los alrededores.

La encuesta con los antiguos residentes mostró en términos generales actitudes favorables a los desplazados, que son vistos sin ninguna discusión como auténticos desplazados. Sólo un I2.5\% de los encuestados opinó que eran gente perturbadora, 
mientras que el $59 \%$ expresó que eran gente que había sido despojada y necesitaba ayuda. En cambio, la mayoría de la población encuestada en el casco urbano de Timbío identifica principalmente consecuencias negativas producidas por la llegada de los desplazados. El 4I.I\% de los encuestados respondió que los desplazados generan "menos oportunidades para acceder a los recursos", el 33.9\% considera que los desplazados "traen inseguridad al municipio". Un I2.5\% expresa que los desplazados "generan sobrepoblación e invasión del espacio público", mientras que otro I2.5\% considera que el desplazamiento no trae ninguna consecuencia para ellos como residentes.

A un porcentaje significativo de los antiguos residentes (45\%) no le gustaría participar en asociaciones con población desplazada. Por su parte, quienes querrían pertenecer a alguna organización y asociación con personas desplazadas no tiene siempre intenciones altruistas. El 27.1\% lo haría "para recibir ayudas del gobierno como los desplazados", mientras que $23.7 \%$ "les gustaría participar para ayudar a los desplazados".

A diferencia de Tibabuyes, en Timbío no existe ninguna duda de que los habitantes de La Laguna son auténticos desplazados. Muchos habitantes los perciben como competidores foráneos -aunque con una justificación para residir allí- pero también como personas que pueden aportar experiencias valiosas y en particular una experiencia exitosa de lograr acceso a la tierra. Este es un punto de vital importancia para la construcción de buenas relaciones con sus vecinos campesinos. Esta situación favorable no se repite en Tibabuyes. El desplazado es simplemente un competidor, muchas veces ilegítimo, y culturalmente muy lejano, que goza de unas ventajas muy frecuentemente juzgadas como ilegítimas.

\section{Conclusión}

Los dos grupos de desplazados en su proceso de reasentamiento han logrado retomar su vida a pesar de las difíciles condiciones. La comunidad de campesinos-indígenas logró obtener el predio La Laguna mediante la reivindicación de sus derechos en la interacción con el Estado colombiano e instancias internacionales y al mismo tiempo se han fortalecido como actores políticos y recuperado y reconstruido elementos de su identidad indígena Nasa. Por su parte los desplazados afrocolombianos reasentados en Tibabuyes, permanecen a la expectativa de lograr conseguir una vivienda propia, aún después de ocho años de haber llegado al sector que actualmente habitan. 
Las condiciones de vivienda en arriendo siguen siendo inadecuadas y con pocas posibilidades de mejorar.

Los niveles de subsistencia y la capacidad de generar ingresos siguen siendo precarios en ambos casos. Las dos comunidades resienten vivamente la pérdida del acceso a recursos auto-apropiados y llama la atención cómo vivir en Bogotá se reduce prácticamente al vecindario inmediato, en el caso de las mujeres afrocolombianas que trabajan esporádicamente sólo salen fuera del hogar al lugar de trabajo. Entre los indígenas se presenta una doble percepción respecto al territorio que se han ido paulatinamente apropiando, los mayores se sienten más relacionados y añoran el retorno al Naya, los jóvenes se sienten ligados a su nuevo asentamiento y ven posibilidades de construir un futuro en Timbío.

Los antiguos residentes perciben a los desplazados de manera ambigua. La solidaridad se mezcla con la desconfianza. Se reconoce en general que la llegada de los desplazados no produce grandes cambios que transformen las dinámicas anteriores dentro de la localidad. Sin embargo, dos elementos clave perturban la relación entre desplazados y antiguos residentes: la duda sobre si el vecino es un "auténtico" o un "falso" desplazado en Suba, y, en los dos casos, la falta de apoyo a los residentes no desplazados por parte de las entidades gubernamentales y no gubernamentales, a pesar de las condiciones materiales de vida similares dentro de situaciones de pobreza y carencia.

En los dos procesos de reasentamiento los desplazados han logrado construir unas nuevas territorialidades en un medio desconocido y muy diferente al de origen. Se han adaptado a los lugares en donde hoy residen. En ambos casos la construcción de un territorio como fuente de recursos es incompleta y las dos comunidades siguen dependiendo de diversas formas de asistencia pública y privada para sobrevivir. Dentro del proceso de adaptación cabe resaltar el desarrollo de habilidades para tejer relaciones con la institucionalidad formal del Estado y con las organizaciones no gubernamentales. Han logrado participar, así sea de manera limitada en muchos casos, en espacios sociales, laborales y políticos y en este quehacer han adquirido la capacidad de organizarse para lograr obtener la asistencia indispensable para la supervivencia en el nuevo lugar de residencia.

Han aprendido a utilizar mecanismos para el reclamo de derechos, pero este aprendizaje permite apenas sobrevivir y reemplaza a una plena autonomía y al ejercicio de una ciudadanía sin mayores restricciones que la de sus vecinos que no han sido víctima del desplazamiento forzado. En ambos casos el lugar de reasentamiento ofrece un pobre consuelo para lo que se perdió y se ve siempre con el lente de lo ingrato. Tibabuyes es algo radicalmente diferente al medio Atrato, pero aún así los 
desplazados afrocolombianos han logrado apropiar elementos de lo perdido donde realizan actividades recreativas que puedan compensar su necesidad de expresión lúdica, musical y asociativa. Para los campesinos-indígenas Nasa residentes en La Laguna, las diferencias son menos radicales, sin embargo la plena utilización del predio no ha sido lograda. La Laguna se ve como una parte del Alto Naya que hace parte del territorio de la comunidad al cual aún todavía no se puede volver.

Los lugares conformados por migrantes pobres se convierten en escenario para la vida conjunta con los residentes que ya estaban establecidos allí, en algunos casos los prejuicios y en otros la solidaridad dan forma a un proceso de restablecimiento de condiciones de vida para unos y otros, crean un paisaje del lugar articulando trabajo material y elementos inmateriales llevados en la memoria y en algunos momentos llegan a procurar una nueva comunidad.

Sin embargo, el orden conocido y familiar del poblador rural, lo que lleva dentro de sí mismo, del grupo al cual pertenecía, es extraño y desconocido (Fernández, 2005) para el medio urbano al que ha llegado. Así el desplazado requiere de otras habilidades; lo sabido, el cultivo de la tierra o las tradiciones, ha perdido vigencia. Los desplazados de esta época como los de otras épocas, forzados por la violencia hacen frente a carencias materiales y carencias simbólicas. Los primeros se hallan dentro del juego social debido a los subsidios que reciben, pero el sentido de su vida resulta marginalizado, descalificado, su autonomía está en entredicho; ambos tienen mínimas posibilidades de poder ejercer su libertad de optar o de decidir por una forma de vida. Dilemas y remembranzas, además de precariedades económicas, temores, dolores y afectos retan a estos grupos de pobladores a construir un nuevo lugar para sí; la ciudad representa un desafío de aprendizajes y discriminación que complejiza sus vidas.

El uso de mecanismos para el reclamo de derechos hace parte de nuevos aprendizajes; así mismo, la espiral de pobreza, de desigualdad de medios físicos, económicos, sociales, marca su proceso de adaptación e integración al nuevo medio, territorio y lugar. Los límites estructurales definidos por el modelo económicopolítico de desarrollo sin real equidad, la violencia política, el conflicto armado, han conducido a una franja amplia de población a confrontarse en un umbral muy alto para acceder a una vida con calidad. Reinventarse para salir adelante es el reto que gravita en su cotidianidad de búsquedas para sobrepasar los límites impuestos por las condiciones histórico-político-económicas en las que se encuentran en el lugar de reasentamiento. 


\section{Bibliografía}

Agencia Presidencial para la Acción Social

2009 Estadísticas sobre población desplazada. Disponible en:

$<$ http://www.accionsocial.gov.co/Estadisticas/publicacion\%2odiciembre\%20de\%202009,htm> [29 de marzo de 20Io].

Alfonso, Ó.

201 "La geografía del desplazamiento forzado reciente en Colombia", en Documentos de Trabajo núm. 33, Facultad de Economía, Universidad Externado de Colombia.

Afrodes (Asociación de Afrocolombianos Desplazados) et al.

2002 Misión de Observación a la Situación de las Comunidades Afrodescendientes en Colombia: Desplazamiento forzado interno, Violaciones al Derecho Internacional Humanitario y Situación de Personas Afrocolombianas en las Cárceles. Anexo 1: Casos específicos sobre acto de violación de los derechos bumanos infracción a los derechos bumanitarios de comunidades negras", Afrodes, cepac et al.: Bogotá.

Cabildo Indígena Nasa Kitek Kiwe

Sitio web $<$ http://comunidadnaya.blogspot.com $>$.

Colombia. Ministerio de Educación Nacional

200I "Serie lineamientos curriculares: Cátedra de estudios afrocolombianos", Ministerio de Educación Nacional, Bogotá.

Consultoría para los Derechos Humanos y el Desplazamiento (codHes)

2009 "Víctimas emergentes: desplazamiento, derechos humanos y conflicto armado en 2008", [en línea] en Boletín Informativo de codHes, núm. 75. Disponible en: <http://www.colectivodeabogados,org/rmg/pdf/ codhes_informa_no_75.pdf > [junio de 2014].

Cresswell, Tim

2009. "Place", en: Nigel Thrift y Robert Kitchen (eds.), International Encyclopedia of Human Geography, vol. 8 (pp. 169-177), Elsevier, Oxford.

Debarbieux, Bernard

2003 "Territoire. Agencement de ressources matérielles et symboliques capables de structurer les conditions pratiques de l'existence d'un individu ou d'un collectif social et d'informer en retour cet individu ou ce collectif sur sa propre identité", en J. Lévy y M. L. Lussault (dirs), Dictionnaire de la géographie et de l'espace des sociétés, Belin, París, pp. 9II-9I2. 
Defensoría del Pueblo

2002 "Resolución defensorial humanitaria No. OI2". Documento electrónico disponible en: <http://www.defensoria.gov.co/attachment/242/humanitariai2.pdf $>$ [enero de 2014].

Fernández Christlieb, Pablo

2005 "Aprioris para una Psicología de la cultura", en Athenea Digital, 7. Disponible en $<$ http://atheneadigital.net/article/view/178 $>$ [mayo de 20I4].

García, P. y E. Jaramillo

2008 El caso del Naya: Desarraigo territorial de poblaciones indígenas, campesinas y afrodescendientes como un objetivo de guerra, IWGIA y Colectivo de Trabajo Jenzerá, Bogotá, 52 pp.

Haesbaert, Rogério

2004 El mito de la desterritorialización. Del fin de los territorios a la multiterritorialidad, Siglo xxi, México.

Instituto Latinoamericano de Servicios legales Alternativos (ILSA)

2006 El limbo en la tierra, reubicación de la población desplazada del Alto Naya. Desplazamiento y retorno, balance de una política, libro 3, ILSA. IGAC, Bogotá.

Instituto Geográfico Agustín Codazzi (IGAC)

2014 Sistema de Información Geográfica para la Planeación y el Ordenamiento Territorial SIG-OT, <http://sigotn.igac.gov.co/sigotn $>$ [diciembre de 2014].

Jimeno, $M$.

201 Kitek Kiwe. Reasentamiento Nasa. Nuestra memoria, Cabildo Indígenas Nasa Kitek Kiwe, Universidad Nacional de Colombia-Centro de Estudios Sociales (CEs), Bogotá.

Le Berre, $M$.

I992 “Territoire”, en A. S. Bailly y D. Pumain (dirs.), Encyclopédie de la Géographie, Economica, París, pp. 617-638.

Lévy, Jacques

2003 “Territoire. Espace à métrique topographique”, en Jacques Lévy y Michel Lussault (dirs.) Dictionnaire de la géographie et de l'espace des sociétés, Belin, París, pp. 907-910.

Lévy, Jacques y Michel Lussault (dirs.)

2003 Dictionnaire de la géographie et des espaces et des sociétés, Belin, Paris. 
Mercier, M.

2009 "Una teoría del lugar", en J. W. Montoya (ed.). Lecturas en teoría de la geografía, Universidad Nacional de Colombia, Bogotá, pp. 2I-40.

Naranjo, G.

s.f. "Ciudades y desplazamiento forzado en Colombia. El"reasentamiento de hecho" y el derecho al restablecimiento en contextos conflictivos de urbanización", disponible en, <http://www.academia.edu/7568806/ Ciudades_y_desplazamiento_forzado_en_Colombia> [abril de 2014].

Ocampo, Myriam et al.

2012 Reconstruir el territorio y reconstruirse a sí mismo: reterritorialización de poblaciones despojadas de su territorio de vida por causa de la violencia armada en Colombia, tomo 2, Reverdecer en el cabildo Kitek Kiwe 'Tierra Floreciente.' Del Cerro Naya a la toma del bastón de mando, Universidad Externado de Colombia, Colciencias, Bogotá.

2014 Reconstruir el territorio y reconstruirse a si mismo: reterritorialización de poblaciones despojadas de su territorio de vida por causa de la violencia armada en Colombia. tomo 4, El río: ritmo y fuente de vida. Delas riberas del Atrato a la construcción de lugares de encuentro en Bogotá, Universidad Externado de Colombia, Colciencias, Bogotá.

Oviedo, C. A.

2010 "Del destierro al fortalecimiento de la identidad étnica: una etnografía desde la comunidad desplazada por la violencia de la Región del Naya". tesis de grado en Antropología, Universidad del Cauca, Popayán.

Ramírez, M.

2002 "Etnicidad e indianidad", en M. Serje, M. Suaza y R. Pineda (eds.), Palabras para desarmar. Una aproximación critica al vocabulario del reconocimiento cultural en Colombia, Ministerio de Cultura, Instituto Colombiano de Antropología e Historia (ICAHN), Bogotá.

Rivera García, A.

2010 "Hans Blumenberg: mito, metáfora absoluta y filosofía política", en Ingenium, núm. 4 julio-diciembre, pp. 145-165.

Thrift, Nigel

1996 "Strange Country, Meaning, Use and Style in Non-Representational Theories", en Nigel Thrift (ed.) Spatial Formations, (pp. I-5I), Sage, Londres. 